\title{
A PAIXÃo de FAZER: \\ SAÚDE MENTAL E DISPOSITIVO GRUPAL
}

\author{
Abrahão de Oliveira Santos $\star$ \\ Douglas Egidio Gomes Nechio ${ }^{\star}$
}

\begin{abstract}
Resumo
No presente trabalho, foi explorada uma experiência de estágio com usuários de um Centro de Atenção Psicossocial - CAPS II - no interior do estado de São Paulo. Trata-se de continuar a produção da reflexão da experiência de estágio e supervisão do projeto de saúde mental realizado nesse serviço do SUS. O interesse foi pensar os efeitos do dispositivo grupal e a produção de intervenções de produção de saúde e subjetividade, na esteira das ferramentas propostas por Nietzsche, Michel Foucault, Lourau, Gilles Deleuze e Canguilhem. Por essa via, o propósito foi realizar intervenções capazes de fazer frente às necessidades colocadas pela Reforma Psiquiátrica.
\end{abstract}

Palavras-chave: grupos; dispositivo grupal; saúde mental; CAPS; subjetividade.

\section{The PASSION FOR DOING:}

\section{MENTAL HEALTH AND GROUP DEVICE}

\begin{abstract}
This work derives from a clinical work experience with users of Centro de Atenção Psicossocial - CAPS II, a center for psychosocial assistance in the State of São Paulo, Brazil. It moves forward into the development of valuable views and insights into the clinical work and supervision activities for the mental health project carried out at this assistance service sponsored by the Unified Health System - SUS. The focal point of this work is to look into the effects of group device and production of interventions aimed at building a sounder health and subjectivity, mostly relying on the tools proposed by Nietzsche, Michel Foucault, Lourau, Gilles Deleuze, and Canguilhem. With this idea in mind, the work has focused its action on interventions that could effectively respond to the needs placed by Psychiatric Reform.
\end{abstract}

\footnotetext{
^ Graduado em Psicologia pela Universidade Federal da Paraíba. Mestrado e doutorado pela PUCSP. Professor adjunto da Universidade Federal Fluminense no Departamento de Psicologia. Pesquisador em Saúde Mental, Sociedade e Subjetivação e desenvolve pesquisa e oficinas em gestão coletivas dos sonhos. Endereço: Universidade Federal Fluminense, Departamento de Psicologia. Campus do Gragoatá, s/ nº bloco O, $2^{\circ}$ Andar, Sala 218, Gragoatá. 24210-350 - Rio de Janeiro, RJ - Brasil

E-mail: abrahaosantos@hotmail.com

$\star \star$ Graduado em Psicologia pelo Centro Universitário Hermínio Ometto.

E-mail:douglas_nechio@hotmail.com
} 
Keywords: groups; group device; mental health; CAPS; subjectivity.

\section{INTRODUÇÃO: O ESTÁGIO}

No presente trabalho, buscamos explorar reflexivamente uma experiência de estágio não curricular na área de saúde mental, em um Centro de Atenção Psicossocial - CAPS II - no interior do Estado de São Paulo. Trata-se de continuar a produção da reflexão da experiência de estágio e supervisão do projeto de saúde mental realizado nos serviços substitutivos do SUS. Interessa-nos pensar os efeitos do dispositivo grupal e a produção de intervenções de produção de saúde e subjetividade, na esteira de ferramentas como a vontade e a saúde, propostas por Nietzsche e Canguilhem; o dispositivo, as linhas de subjetivação e singularização, propostas por Michel Foucault e Gilles Deleuze; análise da demanda, o instituído e o instituinte, propostas por René Lourau. Estes autores, aliados a outros, nos permitem reintroduzir a dimensão do embate histórico das forças na construção e operação dos conceitos, possibilitando-nos uma intervenção que inclua a esfera institucional e inventiva implicada na saúde, e mais especificamente, na saúde mental. São autores que pensam a problemática do cuidado de si, desde o século XIX, como Nietzsche, até a atualidade. Por essa via, pretendemos fortalecer as intervenções clínicas capazes de fazer frente às necessidades colocadas pela Reforma Psiquiátrica.

O projeto de extensão em saúde mental teve início em 2001 no serviço de saúde mental municipal. Representava um esforço do curso de psicologia de se aliar aos avanços da Reforma Psiquiátrica brasileira e preparar profissionais qualificados para os serviços substitutivos que a Reforma propõe. Este trabalho pretende explorar especificamente as experiências que os estagiários extensionistas tiveram com os usuários do serviço de saúde mental relatadas no trabalho Máscaras: saúde mental e subjetivação (NECHIO et al., 2007), no IV Encontro Nacional da ABRAPSO. Neste mesmo encontro foram apresentadas outras reflexões (GALLANO; SANTOS; SENARELLI, 2007; HERGERT et al., 2007; QUEIROZ et al., 2007; SOUZA; SANTOS, 2007), referentes ao mesmo projeto e local, porém com diferentes enfoques ou questões nas intervenções e nos trabalhos escritos.

Depois de algum tempo, de fevereiro a março de 2007, em contato com os frequentadores da sala de espera do serviço e com os usuários do Centro de Atenção Psicossocial (CAPS), as discussões em supervisão levaram os estagiários a propor uma oficina para confecção de máscaras de rosto. Já havia certa familiaridade com os usuários e com o funcionamento do CAPS. Os estagiários se sensibilizaram com as necessidades das pessoas na situação de sala de espera e mesmo dos usuários, para quem os recursos terapêuticos, principalmente quanto aos grupos de expressão verbal, eram escassos ou inexistentes. Viram aí uma situação de semiabandono: longo tempo à espera de atendimento; a medicação como principal recurso terapêutico; inexistência de espaços de conversa com os profissionais de saúde e espaços de trocas de experiências que pudessem dinamizar recursos próprios dos usuários do serviço; nenhuma preocupação com 
familiares; no CAPS, o único recurso terapêutico considerado eficaz, além da medicação, era o atendimento individual dos pacientes delirantes, ao mesmo tempo que a psicóloga não dispunha de conhecimento para psicoterapia de pacientes com transtornos mentais severos. $\mathrm{O}$ atendimento grupal, como oficinas de terapia ocupacional, não tinha força expressiva além da vantagem de os usuários se sentarem um ao lado do outro; ao contrário, nessas oficinas eles deveriam fazer suas "tarefas tapeçaria" em silêncio.

$\mathrm{Na}$ chamada terapia ocupacional com tapeçaria e atividades semelhantes, havia a consigna de fazer as tarefas em ordem a até mesmo em silêncio, para que ninguém incomodasse ninguém com suas bizarrices. Qualquer perturbação era recriminada, de modo que o grupo tinha que se manter na condição inerte, sem lugar para as singularidades tão prementes na loucura. Loucos ou doentes mentais não têm o que falar, não têm que ser, ao contrário, devem calar e não ser. Nenhuma singularidade ali tinha vez, nenhuma fala destoante, nenhum gesto desagradável. Na verdade, as oficinas de terapia ocupacional, tal como eram ali praticadas, seriam tanto mais eficazes quanto maior fosse o silêncio e a boa educação do mínimo de expressividade.

Apesar de estarmos em um serviço substitutivo da Reforma Psiquiátrica, a vivência ali tinha o gosto forte da instituição manicomial. Quando ocorriam encontros coordenados por um profissional de nível universitário, os pacientes não tinham liberdade para expressar-se, nem comunicar-se, nem falar das suas experiências quando estas se tornavam mais distantes do padrão de normalidade, do aceitável e compreensível. Para quem porta a condição da psicose ou transtorno mental severo, senão para qualquer usuário da psiquiatria, esta restrição é desastrosa. Esse quadro impactante mobilizou angústias, questionamentos e ideias de intervenção nos estagiários. Diante dessa situação, a supervisão colocou a necessidade de ampliar os espaços de tratamento e promoção de saúde mental, de fala, de convivência, de trocas de experiências, de produção de signos verbais e não verbais e com isso disparar processos de invenção e produção de subjetividade que dessem força às singularidades constituintes dos usuários, aos seus motivos, histórias, agitações. Entre propostas de oficinas de história e origami veio também a oficina de máscaras, um trabalho para articular coletividade.

\section{O DISPOSITIVO GRUPO}

A escolha das ferramentas da análise institucional, do conceito de saúde, de grupo e coletivo, subjetivação, dispositivo, de vontade, propostas pelos autores citados, marca nosso distanciamento da perspectiva do trabalho da dinâmica de grupo tal como propõe Kurt Lewin. O trabalho da dinâmica de grupo não inclui as perspectivas histórica, institucional nem política. Em vez disso, toma o grupo pela sua interioridade, pelo desenvolvimento de sua capacidade de resolução dos conflitos que se estabelecem no interior do próprio grupo (FENANDEZ, 2006). Certamente ao valorizar o debate e a solução da coletividade, Lewin procura ressaltar os valores democráticos, colocando-os no topo da hierarquia dos funcionamentos dos grupos. Porém, os próprios valores aos quais o grupo está submetido 
não são postos em análise; a demanda social à qual se pretende atender, as normas e regras, que vêm da sociedade e dão a conformação do grupo, não são postas à prova nem levadas em questão pelo coordenador de grupo. A dinâmica de grupo de Lewin pleiteia a "democracia entendida como livre discussão" (FENANDEZ, 2006, p. 79), como modo de aliviar as tensões e resolver os problemas já colocados, mas não se pode recolocar as próprias regras, reformular os valores, os modos de distribuição do poder; não há lugar para a pergunta do por que são esses os nossos problemas e não outros. Ora, as técnicas de grupos assim desenvolvidas estavam engajadas em regular a produção e reverter a potência do grupo para o aumento de rendimento da empresa. Isso justifica o alto investimento estatal e empresarial ainda hoje observado em melhorar as relações humanas e reduzir as tensões dos embates, estes considerados disfunções sociais. Seguindo essa pista, dizemos que o grupo é um dispositivo para dar solução a problemas sociais, no sentido de consolidar as hegemonias instituídas. Aceitamos isso com naturalidade, mas trata-se da consolidação histórica de determinado regime de relações.

Como no caso de todas as ciências, o conhecimento a respeito do grupo surge como exigência das práticas sociais. A análise institucional vai justamente se preocupar em desvelar a demanda social que emerge no vazio constituído no embate das práticas sociais, dirigindo-se logo para a questão do "consenso mínimo que se estabelece entre os atores por intermédio do que é instituído aqui e agora" (LOURAU, 1996, p. 194; grifo do autor) como organização, regra, norma, tarefa, valor ou modo de viver. Engajada em tornar visível certo campo de problemas e se afastando de outros, a psicossociologia de Kurt Lewin investe na análise das relações sociais, tão somente em conformidade com as finalidades econômicas e “pelo sistema institucional da 'sociedade' global" (LOURAU, 1996, p. 199-200). Isso quer nos dizer que o grupo está limitado, sofrendo do destino previamente colocado, sem que possa avançar além de si mesmo, sem que possa se diferenciar, sem espaço para expressão das singularidades, nem criar para si novos valores, novas formas de vida, sem que possa experimentar uma força de criação de si mesmo, sem que possa exercer seu poder de autonormatividade.

Mas em nosso ponto de vista, grupo é apenas um nome, não para se referir ao grupo-ilha, voltado para si mesmo, para promover interação dos indivíduos e, nesse movimento, fortalecer as individualidades ou o sujeito. Grupo, em nosso caso, é o campo das transversalizações e da produção de modos de existência, produção de subjetividade. É o sentido dado por Barros $(1994,2007)$ ao dizer que ao desconjuntarmos a noção de grupo e levá-la ao campo da produção da subjetividade, da potência que há no grupo de engendrar modos de ser e estar, percebemos sua multiplicidade e seu caráter provisório, abandonando a noção de organização grupal, que pressupõe ordem e estrutura, pressupõe sempre o instituído. Para Barros (1994, p. 152), ao concebermos o grupo como dispositivo "acionamos nele sua capacidade de se transformar, se desterritorializar, irromper em devires que nos desloquem do lugar intimista e privatista em que fomos colocados como indivíduos", acionar as forças instituintes. 
Um dispositivo articula um conjunto de várias linhas de natureza distinta, ou seja, uma multiplicidade de possibilidades. Santos (2006) fala de uma grupalidade que escapa da coerção da organização, forma ou mesmo estrutura, que pode germinar e multiplicar-se, aliás, transversalizar-se, conectar aquilo que em dado momento lhe é exterior. O coletivo que aí se apresenta se traduz numa "potência maior, que produz e distribui mais potência, nutrindo e criando a si próprio e às individuações que aí se compõe" (SANTOS, 2006, p. 126). Desta maneira o grupo não é, mas em inverso disso, continuamente vem a ser, traz consigo o novo, não está instituído; é visto como uma teia complexa de relações intersubjetivas que se influenciam mutuamente, produzindo novas vivências e singularidades. Assim o grupo é aquilo que pode nos oferecer uma gestão para alcançarmos o lado de fora, isto é, para experimentarmos o que ainda não somos, para existirmos de outro jeito. No encontro no qual falamos da nossa vida, das fraquezas, das vontades, dos destinos, dos impasses e dos exercícios de liberdade - encontro no qual experimentamos, da vida, suas mais diversas máscaras, realizamos essa construção de nós mesmos, do que em nós é questão, prisão ou destino de liberdade, isso que chamamos subjetividade, que são os modos do acontecer da vida. Um grupo que brinca com as máscaras, que experimenta as faces sérias das máscaras, está dando a si o direito à diferença, à variação, à expressão das singularidades. É o que, no dispositivo, Foucault chamava linha de subjetivação (DELEUZE, 1990). A subjetividade é o modo de vida único que se concretiza. Então não tomaremos a subjetividade como entidade, mas como o fluxo das expressões que ganham consistência nas práticas.

O caráter ativo já caracteriza o grupo como um dispositivo, diz Barros (1997). O grupo dispõe, propõe, cria campos de fala e planos de transformação de modos de vida (subjetividade); força o aparecimento de certas falas e suprime outras; o grupo se estabelece com dinâmicas, isto é, produz e distribui forças e relações de poder. Este é um exercício de gestão de si ou de autonormatividade, das condições que nos compõem, de criação de autonomia, como propõe a análise institucional. Saber, Poder e Subjetividade são linhas de processualidades que atravessam o dispositivo, tal como o pensa Foucault (DELEUZE, 1990). As primeiras duas dimensões de um dispositivo são as linhas de visibilidade e as linhas de enunciação. O dispositivo faz ver e faz falar. E como toda a luz que ilumina um campo colocando um outro na sombra, o dispositivo pode fazer desaparecer um objeto que não existe sem a luz, ou pode impedir de vir à tona certas falas. Assim em cada extrato "existem camadas de coisas e palavras" (BARROS, 1997, p. 186), formas, expressões e conteúdos, que passam a existir ou deixam de existir, segundo o dispositivo. Aquilo que alguém diz que vê, o valor de uma fala, a experiência de sofrimento ou de saúde daqueles que passam pelos serviços de saúde mental são afirmados ou negados segundo o dispositivo que lhes dá lugar ou os suprime. A sala de espera, o consultório médico, a rua, a gangue de adolescentes, a feira-livre, encontros numa oficina de trabalhos, lavadeiras ao rio lavando suas roupas brancas, o louco andando pelas ruas: cada estrato abre para um campo de falas e de coisas; cada estrato constituído no tempo e no espaço dá legibilidade, visibilidade e legitimidade a certas formas de vida, a certos modos de expressão. 
O consultório, o encontro médico-paciente, torna visíveis as enfermidades, as deficiências, certo plano de assimetria, dá ao corpo seu plano de ação na carência, na deficiência, na doença. Na História da loucura Foucault (1995) mostra como o asilo isola e torna visível a loucura, impõe-lhe uma natureza primeiramente amoral e perigosa e, simultaneamente, estabelece o estrato, as condições sociais de segregação da loucura silenciada e tornada doença mental e lança as bases para o surgimento da psiquiatria que pode dar-lhe tratamento. Uma primeira leitura de Foucault e sua historicidade, que, em vez de buscar as origens, promete-nos fazer ver como os objetos tornam-se visíveis ou enunciáveis em cada época (FOUCAULT, 1986; DELEUZE, 1998), traz certo temor diante da trama na qual o poder se constitui. Mas, de outro lado, podemos nos nutrir de forças de ação, diante da visibilidade das possibilidades de, inversamente, investirmos na criação de estratos de socialidade que deem lugar a outros conteúdos, a outros modos de expressão. Lugares de socialidade, de convívio que estabeleçam novas formas de ver e fazer ver a loucura. Sobretudo criarmos os espaços para que parte da população pobre que porta o estigma do rótulo da psicose ou transtornos mentais severos alvo da instituição psiquiátrica, tenha sua palavra validada, para legitimar esses outros locutores. Talvez o maior dos benefícios que a leitura dos textos de Foucault nos proporcione seja que possamos buscar as condições que abram para experimentação de outras sensibilidades, da experiência real, como lembra Deleuze (1998) em seu absoluto pragmatismo, condições únicas para as singularidades que compõem uma experimentação dos modos de viver. Aquelas condições que nos fazem penetrar nas incertezas, que reclamam nossa aposta no próprio devir que ali se apresenta, na expressão que a vida desenvolve. Desenvolve ali e vai, amanhã, poder reclamar e investir em outros lances, pois trata-se de considerar esses lugares de nova socialidade como lugares de passagem, de um tempo no qual se gestam as novas mutações. Que os espaços de convivência que aí se criam apenas sejam um momento de abertura do futuro e jamais o novo lugar no qual a loucura deverá estar confinada.

Espaços de convivência, de criação, de realização de atividades manuais são alguns dos termos que definem a oficina, para Galletti (2004). Mas o mais importante para Galletti (2004) é que a oficina não seja naturalizada como espaço para tratamentos de doentes. E necessário que possamos fazer uso desse recurso oficina para produzir diferenças, construindo as oficinas como dispositivos, no sentido anteriormente colocado. A oficina,assim, é um espaço heterogêneo, sem submeter-se à marca de uma especialidade disciplinar, podendo escapar do modelo normalizador e enveredar na perspectiva da reinvenção da vida. Essa perspectiva vai no mesmo sentido de Santos (2006, p. 24) para quem a oficina deve deixar o compromisso normalizador e "constituir um espaço real de vida". Nesse sentido a oficina é aqui pensada como dispositivo.

\section{A Questão da SAÚde}

O grupo-dispositivo era então nossa estratégia no cuidado dos usuários do serviço psiquiátrico, na produção de subjetividade, na produção da saúde. Nossas ciências têm dificuldade em abordar a saúde em sua positividade (ALMEIDA 
FILHO; COELHO, 2002), sem desviar-se para sua negatividade, a doença. Almeida Filho e Coelho suspeitam da influência da indústria farmacêutica e de uma cultura da doença e falam da reação, desde a década de 1970, contra a expropriação da saúde. A Organização Mundial da Saúde (OMS) considera a saúde não apenas a ausência de doenças, mas, o bem-estar físico, psíquico e social e sugere, inclusive, para reduzir a carga dos transtornos mentais, "promover estilos de vida saudáveis" (OMS, 2001, p. 42). A promoção de estilos de vidas saudáveis vem, entretanto, conduzindo a um enrijecimento na direção de estabelecer modos de vida recomendáveis e à censura, outra vez, das opções desobedientes, dos modos de vida dissidentes; à censura dos outros modos de subjetivação que não aqueles do padrão da sociedade. Isso pode ser consequência dessa noção demasiadamente geral e abstrata, preconizada a partir de um ideal de saúde, de bem-estar, de um modo universal de ver o homem. Referir-se à saúde como um bem-estar ideal é pôr a possibilidade de desvalorização e de exclusão daquilo que é considerado indesejável em um dado momento pela sociedade. Daí as estratégias de controle antecipado de doenças e dos "programas de saúde" que vemos perfilar-se aos nossos olhos, como a política do antitabagismo. Novamente, trata-se de conceber a saúde sem considerar as potências de afeto, as singularidades, os modos de vida reais, as tradições, as diferenciações que nos ocorrem.

Para Nietzsche (2001, § 120), não existe saúde em si, pois isso depende dos objetivos, dos horizontes de cada um, das suas forças, dos seus ideais, dos limites. Por termos o dogma de que todos os homens são iguais, denuncia Nietzsche, imaginamos conseqüentemente uma saúde igual para todos. A saúde de cada um depende não de um modelo universal de saúde, mas depende do modo como cada um pode, deseja ou precisa participar do social. Então, há muitos modos de saúde, que são modos de participação, que são exercícios de saúde e talvez devamos considerar, como Nietzsche $(2001, \S 289)$, que também os infelizes, os que não fazem parte da norma, as formas dissidentes, tenham seu direito e seu raio de sol, também os antípodas tenham direito à existência. Participação, no entender de Santos (2006), diz respeito ao acontecimento que se desdobra "entre" os corpos, os afetos. Bezerra Jr. (2007) lembra que para Canguilhem saúde não é a ausência de sintoma, não é a negação da doença. "Saúde significa capacidade de poder suportar embates, sofrimentos, limitações e ir adiante, construindo novas formas de existência" (BEZERRA Jr., 2007, p. 28). Muito cedo Nietzsche, cujas obras certamente inspiraram Canguilhem, vê a doença como acesso a outros modos de pensar, a forças plásticas e curativas, e, portanto, como meio do espírito lançar-se a verdadeiras aventuras, como a aventura da criação de si. O erro e o mundo infiel (NIETZSCHE, 2000, § 4, Prólogo; § 33) fazem parte da vida e a levam adiante, a inventar novos mundos, valores, estéticas. Canguilhem segue estas pistas no estudo do binômio normal-patológico das ciências biomédicas, para ver a saúde como capacidade normativa. Saúde é uma força positiva que cada indivíduo tem de manter para si mesmo sua concepção de saúde. "Saúde é a capacidade de ultrapassar a norma", define Canguilhem (1990, p. 158). Este pensamento se afasta assim da ideia de que os indivíduos saudáveis seriam aqueles que se adaptam às realidades preexistentes, a uma norma. Os desajustes, as infidelidades do meio, como fala 
Canguilhem, os erros, são parte também de um processo de saúde e das condições de transformação do homem e da realidade, do devir. Ter saúde é poder desenvolver a vida que há em si, é a vida em sua variação, desenvolver o poder de afetar e ser afetado, isto é, a vontade de potência (DELEUZE, 1997). Como potência de variação dos modos de vida, saúde implica processos de subjetivação.

\section{A oficina de máscaras}

É por essa sensibilidade com relação à saúde que o projeto de extensão em saúde mental se orienta e se expressa na intervenção dos estagiários. Ancoramo-nos conceitualmente numa perspectiva de grupo e de saúde que leva em consideração a singularidade de seus participantes e pensa os embates sociais nos dispositivos de modos de existência e de criação, como colocamos a partir dos autores citados.

A oficina de máscaras ocorreu no período de abril a dezembro de 2007 , com encontros semanais, durante uma hora e meia de trabalho, coordenada por dois estagiários. Era um grupo formado por cerca de 15 pessoas de diferentes idades, comportando desde adolescentes até idosos, de ambos os sexos, usuários do serviço de saúde mental que vieram participar da atividade de máscaras. Reuniam-se para fazer máscaras, aquelas que usamos em bailes de mascarados, e falar de suas vidas. O material utilizado, para tal confecção, contava com cartolina, lápis de cor, giz de cera, cola colorida, cola comum, guache e pincéis; matérias-primas com as quais cada um, a seu modo, dava expressão a sua vontade de revestir a vida do seu jeito com as máscaras, cores e misturas que podiam lhe dar. Havia também modelos de máscaras que eram apresentados com o intuito de instigar a produção. Havia o risco de os usuários tomarem esses modelos como padrão, mas pelo contrário, a alegria experimentada na oficina estava justamente nas variações, criativas e pulsantes, que despertavam sorrisos, sussurros e exclamações. Eram as subjetividades se constituindo nas linhas das suas variações em relação a todo padrão, nas linhas das singularizações de si, como falam Foucault e Deleuze; a saúde, enquanto capacidade para inventar-se, ultrapassa as normas, como falam Nietzsche e Canguilhem.

Assim a oficina ia prosseguindo. Em vez de bloquear discursos e tendências que inicialmente parecessem bizarras, como ocorre frequentemente nas práticas psiquiátricas hegemônicas ou manicomiais, os conceitos de dispositivo e de multiplicidade nos permitiram intervir no sentido de potencializar as falas heterogêneas, somar, multiplicar as ideias e sustentá-las, mesmo quando não convergiam numa suposta coesão grupal lewiniana, mesmo quando nos faziam experimentar um grupo estraçalhado e caótico. E não eram poucas as vezes que isso ocorria. O dispositivo grupo, tal como o praticamos, aí estava para criar espaços para que as singularidades ganhassem expressão, para fazer falar, fazer ver a partir de perspectivas diferenciadas; para entrarmos nas linhas de subjetivação e rearranjos subjetivos.

Em certa ocasião, um dos usuários manifestou o desejo de escutar música. O grupo foi convocado a opinar, a considerar o pedido e suas repercussões, a verificar os recursos e sugerir soluções; foi possível coletivizar a demanda. Aquilo 
que era uma oficina de máscaras, desdobrou-se para dar lugar às sonoridades, às musicalidades, a outro campo de afetos, dispondo de novas transversalidades para as quais o dispositivo abria, conectando com outras instâncias da cultura, a música, mas também o rádio, e através dele a cidade toda. A reunião ganhava liberdade por ser promovida pelos estagiários, aumentava o nível de agitação, dava lugar à variação, à experimentação com falas, gestos, modos de ser e a uma ponta de caos e até mesmo de perda do sossego de alguns. Quando o grupo experimenta agitação e vivacidade, isso promete.

O pensamento da ordem, da valorização do equilíbrio e da quietude teme essa ponta de caos e aposta na sua inoperância, como se inoperante não fosse o estado de inércia que o equilíbrio e a ordem exigem. O pensamento anticaos crê que nesse jogo com o desequilíbrio produzido no encontro, no avivamento das forças do coletivo, da multiplicidade e da singularidade que atravessam o grupo, daqueles que vivem a condição da psicose, nada se efetua, nenhuma decisão, nada logra negociação. Este pensamento faz parte do consenso mínimo (LOURAU, 1996, p. 194; grifo do autor) entre os atores sociais, daquilo que é instituído como organização, regra, norma, tarefa, valor ou modo de viver. Nesse consenso se constitui a demanda social de fazer calar a loucura, de silenciá-la, e expulsála do seio da sociedade, como se a loucura, uma vez chamada doença, não mais se compusesse na cultura, nas relações. É fazer calar tudo o que se apresenta no dissenso e aponta outras formas de subjetividade, outra política de verdade além dos interesses dominantes.

Mas liberar os quereres constrangidos pela autoridade médica leva-nos à produção de mais quereres, como o de fazer acordos, de fazer sociedade, e estabelecer amizades e alianças, alcançar metas, superar o estado de coisas atual e pôr em funcionamento a efetuação de virtualidades, vontades que querem se efetuar, ganhar consistência. Liberar os gritos das vontades não reconhecidas, das singularidades polêmicas disparadas pelo aparentemente simples tema de ouvir. Assim se efetua, antes de tudo, a necessidade da gestão da vida e a potência de gestão do coletivo. Sucedeu ao grupo decidir escutar músicas, tendo seus cantores prediletos. Em vez de o caos propagar-se até a anarquia absoluta, o grupo, renovado, recuperado suas forças de criar regras para sim mesmo, de inventar formas de si, reordenou a produção e uma nova série de máscaras. Era a constatação real da produtividade oriunda do caos, da força grupal. Era o exercício da saúde. O dispositivo faz falar, muda o regime de verdade, o que tem validade e o que não tem, redistribui as forças, reconstitui os modos de existir, valida as variações, efetua subjetividades. Em vez de manter o silêncio das diferenças e das vontades, a oficina de máscaras foi um dispositivo que abriu o território para as muitas vozes desse estrato enclausurado que chamamos transtornos mentais severos. Nesse momento o dispositivo que articula os usuários egressos de longos internamentos dos macro-hospitais - submetidos aos maus-tratos, ociosidade, impregnação medicamentosa, falta de projeto terapêutico (REDE, 2004) - faz ver e faz falar outros objetos, faz aparecer certos pontos de vista, "camadas de coisas" (BARROS, 1997, p. 186), palavras, vontades, expressões, forças, que passam a existir ou deixam de existir, segundo o que o dispositivo dispõe. Vozes, 
gestos, vontades, potência de efetuação surpreendiam até mesmo os seus autores. A produção das máscaras e as falas nos traziam surpresas e desnaturalizavam as condições da doença: "nunca pensei que eu pudesse fazer uma máscara assim"; ou: "olha minha máscara, pensava que não ia conseguir desenhar nada". As posições e potências de responder às infidelidades da vida mudavam, como a de uma mulher que não queria participar, alegando não saber fazer máscaras: "eu não sei fazer, quem irá gostar disso"; mas nos surpreendeu a todos e a si mesma semanas depois: "eu produzo máscaras, óculos, eu sei fazer". Eu produzo, eu vou além de mim, eu recrio a realidade, as condições de vida, eu faço saúde, pude refazer-me de outro modo. A saúde como força instituinte, como variação, singularização, como criação de modos de vida.

Deparamo-nos também com elementos reativos que dificultavam o processo criativo, pois tentavam bloquear os gestos, as falas e expressões dos outros pela via da negação. Não eram incomuns, na oficina, discursos autoritários que incessantemente buscavam homogeneizar os pensamentos e sufocar a ação liberadora do grupo. Algumas máscaras, cujo conteúdo remetia ao sofrimento, ao pânico e à morte, eram rejeitadas por estes discursos, causando um mal-estar da ordem da interdição em nosso meio. Este foi o caso da máscara "Pânico". Seu desenho era de um rosto negro, como era negro o rapaz que a fez, banhado pelo sangue e pela dor. Em sua face nebulosa se atravessava uma espessa faca, que lhe formava um rasgo em nada simétrico. Era a máscara simulacro, Pânico, o horror da morte que é tão próxima na experiência da psicose, retrato da alma negra sofrida. O filme Pânico se popularizou pela máscara - e talvez unicamente por isso - que é a cara horripilante e sem sentido da morte. Esta máscara horrorizou os usuários, promoveu indignação e hostilidade. O repúdio da máscara se estendia ao seu criador, um menino ainda adolescente que dificilmente se adequava às condutas médicas. A loucura causadora de espanto e elemento a ser combatido. A beleza e poder de afetar, o impacto da máscara que até nome ganhou, Pânico, também fascinou e foi acolhida, e em vez de sofrer a maldição do julgamento pôde ser apreciada enquanto expressão do tormento humano. Tristeza, alegria, morte, vida, querer e não querer, afirmação e negação. Tudo afirmado na multiplicidade grupal, o grupo como encontro das multiplicidades. Momentos de produção de discursos, de diálogos e de coletividade, de mudança de percepção. Por vezes é preciso falar da morte, para tocar a vida e torná-la uma possibilidade da existência. A questão do suicídio e da morte é difícil, muitas vezes travada, mas pudemos dar-lhe lugar e sustentá-la sem sucumbir aos seus perigos.

A estratégia manicomial presente não apenas nos dispositivos médicos de tratamento da loucura, mas em toda a rede social, interdita alguns assuntos, negaos, recusa as disposições humanas de ir em direção aos seus limites, inclusive ao limite absoluto da morte - esta mesma estratégia também pode se apresentar nos usuários do CAPS. Um senhor ameaçou jamais falar com uma senhora que ameaçava se matar e exigiu dela o silêncio sobre este assunto, que não repetisse a história de sofrimento que a levara a pensar em tirar a própria vida. A intolerância, o sufocamento da dor e também das singularidades e das histórias. Às vezes o discurso cristão irrompia na atividade como forma de exorcizar um problema. 
Notamos o discurso evangélico-cristão cada vez mais presente entre os pacientes psiquiátricos nos serviços de saúde mental. Do modo como aparece nos serviços, na atividade de máscara não era exceção, parecia querer identificar rapidamente e julgar as manifestações de discordância, de discrepância, de diferença e de algo que pudesse colocar em questão a vida e os "dogmas" da normalidade. A produção de máscaras, de figuras tristes ou mórbidas, denotava o tom de sofrimento que pairava nos participantes e os signos não verbais podiam sustentar e dar lugar ao que os discursos recusavam. As "márcaras-óculos" nos permitiam ver de ângulos diferentes, talvez por nos protegerem do pesadume insuportável que traria a visão direta. Olhar pelas máscaras, como Perseu, que olhava a Medusa pelo reflexo de seu escudo. A Meduza-intolerância era reconduzida pelo dispositivo-oficina de máscaras para o confronto coletivo da questão da intolerância; a oficina reconvertia os discursos, pois afirmava a coletividade, o debate, a multiplicidade, a gestão dos impasses humanos, dos seus terrores, dos limites, enquanto definição de saúde.

\section{SAÚde, A PAIXÃo de FAZER: FiNALIZAÇão}

As tensões e as experimentações com a ponta de caos liberadas no dispositivo, longe de acarretar prejuízos à saúde, significavam ricas possibilidades de vida, produção de afetos, enunciados e variação de modos de ser: rica disposição de produção de saúde. Ficávamos perplexos ao final de cada reunião com as situações emergentes. Novidades nos surpreendiam, como quando uma senhora levantou-se e correu para me mostrar o seu desenho. A senhora que até então jamais se dedicara a confeccionar uma máscara e permanecia sentada, quase de costas para o grupo, inspirando medo ou repulsa, às vezes cantava, outras permanecia melancólica, reclinada sobre a cadeira, muda; fazia o esforço de falar tão-somente para perguntar se já tinha acabado a oficina. Nesta oficina, porém, fora arrastada pela paixão de fazer, a paixão inocente de criar, o sagrado sim, o espírito que "agora quer a sua vontade" como Nietzsche (1995, p. 45) nomeava uma das três metamorfoses, a que é capaz de criar nova vida para si, uma nova saúde, novas formas de vida. Não bastasse isso, depois de mostrar seu desenho, cantarolou algumas canções para nós. Falou prolongadamente de si e arrastou o grupo inteiro para ouvi-la. Era o dispositivo grupo operando desde o silêncio e no acúmulo de imperceptíveis movimentos de saúde, a nos presentear com a beleza desta produção. Se o leitor desconfia da potência grupal de aumentar a potência de afetar e ser afetado, o que diria da outra moça a falar, enquanto todos se concentravam em desenhar e pintar: "encontrei aqui um motivo para gostar de mim". Porque, apostamos em dizer, aquele que tem forças para querer a sua vontade, tem forças para gostar de si, para entrar em subjetivações positivas.

As transformações engendradas, bem como os pontos de ruptura e enrijecimento criados pelo grupo, eram processos que davam visibilidade aos dramas de vida, às linhas emaranhadas constituintes da subjetividade. É nisso que consiste o trabalho do dispositivo grupo (BARROS, 1997): invadir os bloqueios, ocupar os territórios inóspitos do viver, os nossos desertos. Quando não se parte de categorias prévias bloqueadoras ou limitadoras do que podem as pessoas, quando desnaturalizamos a doença e abrimos para todos um campo de expressão, como 
na oficina de máscaras, cria-se um lugar para habitar o novo, novas manifestações, como o sorriso daqueles considerados mais apáticos que surgiam diante dos desenhos da máscara, surgidos de suas próprias mãos; ou mesmo as lágrimas já não mais solitárias, não mais do abandono, mas acolhidas e reconhecidas no grupo que as amparava. Aumentavam os encontros e as conversas cresciam, assim como a capacidade de escutar. Falava-se nas paixões e afetos, todos arrastados pelo devir-máscara, as várias máscaras que permitiram falar, ser e ver diferentemente, as máscaras-óculos. As máscaras-óculos foram invenções de quem dizia não gostar de desenhar, não saber desenhar e lamentar-se, pois tudo o que escrevinhava eram rabiscos. Surpresa com sua própria criação, uma máscara no formato de óculos, a moça mudou a percepção de si, enxergou-se de outra forma produtiva e reconheceu-se potente no poderoso olhar das lentes que ela própria havia criado.

"Encontro aqui um lugar que nunca tive para falar da minha vida", era a fala de incontida alegria. A cada nova máscara novas alegrias advindas da criação, do gosto de si no coletivo. A experimentação dos modos de se apresentar se fortalecia e tomava novas formas a cada encontro, fazendo-se saúde e modos de vida. O grupo dispositivo de multiplicidades se configura como experiência rica de subjetivação, gestão da vida e produção de saúde; potencializa a diferença e a sustenta, não hierarquizando modelações nem padronizando modos de existência. A atividade de máscaras mostrou-nos o quanto o grupo pode ser uma potência maior, produzindo singularidades e desejos, agindo como um fortalecedor da vida, expandindo os limites, criando territórios de saúde. 


\section{REFERÊNCIAS}

ALMEIDAFILHO, N. de.; COELHO, M. T. Á. D. Conceitos de saúde em discursos contemporâneos de referência científica. Hist. Cienc. Saúde-Manguinhos, Rio de Janeiro, v. 9, n. 2, maio/ago. 2002. Disponível em: $<$ http://www.scielo.br/scielo. php?pid=S0104-59702002000200005\&script=sci_arttext $>$. Acesso em: 13 ago. 2008.

BARROS, R. D. B. Grupo e Produção. Saúde e loucura: grupos e coletivos. São Paulo: Hucitec, 1994.

BARROS, R. B. Dispositivos em ação: o grupo. In: LANCETTI, A. Saúde Loucura: subjetividade. São Paulo: Hucitec, 1997.

BARROS, R. B. Grupo a afirmação de um simulacro. Porto Alegre: Sulina/ UFRG, 2007.

BEZERRA JUNIOR, B. Um apelo à clínica: nem o respaldo da norma, nem o extravio na dor. In: LOBOSQUE, A. M. (Org.). Caderno de Saúde Mental. Belo Horizonte: ESP-MG, 2007. p. 21-32.

CANGUILHEM, G. O normal e o patológico. Rio de Janeiro: Forense Universitária, 1990.

DELEUZE, G. ¿Que és un dispositivo? In: . Michel Foucault, filósofo. Barcelona: Gedisa, 1990. p. 155-161. Disponível em: <http://www.unb.br/fe/tef/ filoesco/foucault/art14.html>. Acesso em 24 jul. 2008.

DELEUZE, G. Para dar um fim ao juízo. In: . Crítica e clínica. São Paulo: Editora 34, 1997. p. 143-153.

DELEUZE, G. Foucault. São Paulo: Brasiliense, 1998.

FENANDEZ, A. M. O campo grupal. São Paulo: Martins Fontes, 2006.

FOUCAULT, M. Microfísica do poder. Rio de Janeiro: Graal, 1986.

FOUCAULT, M. História da Loucura. São Paulo: Perspectiva, 1995.

GAllano, J. C.; SANTOS, A. O.; SENARELli, R. M. Promoção de saúde mental na sala de espera. In: ENCONTRO NACIONAL da ABRAPSO, 14., 2007, Rio de Janeiro, Anais, 2007. Disponível em: <http://www.abrapso.org.br $>$. Acesso em 23 out. 2008. 
GALLETTI, M. C. Oficina em saúde mental: instrumento terapêutico ou intercessor clínico? Goiânia: UCG, 2004.

HERGERT, L. S., et al. Era uma vez... uma experiência de contar história em sala de espera. In: ENCONTRO NACIONAL da ABRAPSO, 14., 2007, Rio de Janeiro, Anais, 2007. Disponível em: <http://www.abrapso.org.br>. Acesso em 23 out. 2008.

LOURAU, R. A análise institucional. Petrópolis: Vozes, 1996.

NECHIO, D. et al. Máscaras: saúde mental e subjetivação. In: ENCONTRO NACIONAL da ABRAPSO, 14., 2007, Rio de Janeiro, Anais, 2007. Disponível em: <http://www.abrapso.org.br>. Acesso em 23 out. 2008.

NIETZSCHE, F. A gaia ciência. São Paulo: Cia. das Letras, 2001.

NIETZSCHE, F. Humano demasiado humano. São Paulo: Cia. das Letras, 2000.

NIETZSCHE, F. Assim falou Zaratustra. Rio de Janeiro: Bertrand Brasil,1995.

ORGANIZAÇÃO MUNDIAL DA SAÚDE. Saúde mental: nova concepção, nova esperança. Lisboa, 2001. Relatório sobre a saúde no mundo. Disponível em: $<$ http://www.who.int/whr/2001/en/whr01_po.pdf>. Acesso em: 10 abr. 2009.

QUEIROZ, C. C. A. et al. Dobradura: intervenção na sala de espera. In: ENCONTRO NACIONAL da ABRAPSO, 14., 2007, Rio de Janeiro, Anais, 2007. Disponível em: <http://www.abrapso.org.br>. Acesso em 23 out. 2008.

REDE Nacional Internúcleos da Luta Antimanicomial. Relatório da Inspeção Nacional de Unidades Psiquiátricas. 2004. Disponível em: <http://www.pol.org. br/pol/export/sites/default/pol/publicacoes/publicacoesDocumentos/Relatorio_ inspecao_unidades_psiquiatricas.pdf $>$. Acesso em: 21 ago. 2008.

SANTOS, A. de O. Psicose: questões de vida e morte. São Paulo: Vetor, 2006.

SOUZA, L. S., SANTOS, A. de O. O grupo de sala de espera como disparador de subjetividades. In: ENCONTRO NACIONAL da ABRAPSO, 14., 2007, Rio de Janeiro, Anais, 2007. Disponível em: <http://www.abrapso.org.br>. Acesso em 23 out. 2008 .

Recebido em: março de 2009

Aceito em: dezembro de 2009 